\title{
NOTAS LINGÜÍSTICAS (II)
}

Francisco ABaD NEBot

UNED. Madrid

\section{RESUMEN}

En estas Notas aludimos a la historia riojana y a algunas de sus manifestaciones idiomáticas: las Glosas Emilianenses y Berceo, subrayando el carácter globalmente «iberorrománico» de las primeras.

Asimismo se enumeran rasgos vocálicos y consonánticos del Fuero de Ledesma - dialectalmente leonés-, y se plantea la necesidad de estudio (y las fuentes de la documentación sobre repoblación y linguíistica de Málaga y su provincia.

1. Historia y lengua de la Rioja MEdieval

\section{La historia}

Varios datos de geografía histórica referidos a la Rioja en los tiempos medievales fueron tenidos en cuenta por Menéndez Pidal en su ordenación de los Documentos Lingüísticos del Reino de Castilla: al robustecerse en el siglo $\mathrm{X}$ el reino de Navarra, su rey Sancho García (es decir, Sancho Garcés I) reconquistó Viguera, y Ordoño II de León tomó Nájera para cedérsela al monarca navarro; en efecto -interpretará Antonio Ubieto a su vez-, los cristianos pamploneses 
inician la Reconquista a principios del siglo $\mathrm{X}$ con esta incorporación a la cristiandad de las poblaciones de Nájera y Viguera '.

En definitiva lo que ocurrió es que

dos siglos estuvo en poder de musulmanes la Rioja, hasta por los años 922, en que el rey Sancho García de Pamplona la ocupó casi completamente [...]. Desde entonces, a pesar de grandes invasiones musulmanas como la que acarreó el [...] desastre de Valdejunquera, la Rioja se mantuvo navarra ${ }^{2}$.

Luego vendrán las sucesivas incorporaciones de la Rioja al reino de Castilla: de 1076 a 1109 , de 1135 a 1162 , y la definitiva de 1176; hay un documento de 1126 en que los najerenses se consideran ya "castellanos», a diferencia de los francos establecidos allí: «Nazara; .....Sunt autem testes de francis: ..... De castellanis:domnus Sancius.....» ${ }^{3}$.

Los presentes datos los tuvo asimismo presentes Pidal en su otra obra Orígenes del español ${ }^{4}$, y varios de ellos han sido evocados luego por la crítica posterior ${ }^{5}$.

Las expediciones musulmanas que llevaron el castigo a Valdejunquera (920) y Pamplona (924) han estado estudiadas por su parte por José María Lacarra, quien evoca cómo en efecto el reino de Pamplona estaba resurgiendo con el gobierno de Sancho Garcés, y concluye su análisis de detalle y matizado con estas comprobaciones:

Las adquisiciones de Sancho se consolidaron. La incorporación de la Rioja Alta a la España cristiana fue definitiva. El sucesor de Sancho, García Sánchez, habita en Nájera, donde tenía su palacio real: él y su madre doña Tota dicen reinar en Pamplona y Najera ${ }^{6}$.

Tras esta liberación de territorios riojanos por Sancho Garcés I -añadirá el propio Lacarra en otro lugar-, en los monasterios riojanos se va a centrar

1 UbIeto, A.; Reglá, J.; JOVER, J. M.; SeCo, C. (1990): Introducción a la Historia de España, Barcelona, Teide, 18" edicion, p. 152.

2 Menéndez Pidal, RAMón (1966 -reimpresión-): Documentos Lingüisticos de España. I. Reino de Castilla, Madrid, CSIC, pp.108-109.

${ }^{3}$ Ibid., p. 110, y el testimonio documental en p. 112.

4 \$97. 4.

5 Saben a poco - no obstante- las referencias históricas que inician la eruditísima obra de DiAz y DIAZ, MANUEL C. (1979): Libros y librerías en la Rioja altomedieval, Logroño, Diputación Provincial, pp. 11 y ss.

6 LACARRA, J. M. (1971): «Expediciones musulmanas contra Sancho Garcés (905- 925)», recogido ahora como cap. III de sus Estudios de historia navarra, Pamplona, Ediciones y Libros. 
el gran foco de cultura del reino, que es incluso (en su estimación) uno de los más notables de la cultura monástica peninsular ${ }^{7}$.

El camino de Santiago atravesaba la Rioja; primeramente iba más a cubierto de las incursiones musulmanas, pero según recoge Menéndez Pidal,

a principios del siglo XI el rey Sancho el Mayor lo mudó por Nájera a Briviesca, Amaya y Carrión [...]. A fines del mismo siglo y a partir del pueblo de Santo Domingo de la Calzada, el camino se dirigió algo más al Sur, para pasar por Belorado y Burgos; entonces fue cuando Alfonso VI de Castilla rehizo todos los puentes de tránsito desde Logroño a Santiago.

A lo largo de este camino francés había -sobre todo luego en el siglo XII, concreta don Ramón- «barrios especiales poblados de franceses»: ya queda aludido el testimonio de un documento referido a Nájera, por el que sabemos que había allí gentes francesas ${ }^{8}$.

Nos situamos en el tercio inicial del siglo XI, y por entonces interpreta el mismo Pidal en otro de sus trabajos que Sancho el Mayor representaba las aspiraciones feudales que privaban en Europa y que a la vez tuvo la ambición de dominar en gran parte de los reinos cristianos peninsulares 9; no obstante, parecen contradictorios el designio feudal y ese supuesto afán imperialista. En tal sentido se orienta quizá Antonio Ubieto, quien advierte que el conde de Castilla García pasa a ser vasallo de Sancho a cambio de protección política y militar.

El monarca navarro -escribe este investigador- se dedicó a comprar territorios y posesiones en Castilla, otorgando títulos condales a la nobleza de la región. No pretendió con ello traicionar a Castilla, sino asegurar el sistema feudal que habia decidido establecer en la Península. [...] El desconocimiento de la existencia de esta idea feudal en la España del siglo XI ha hecho que [...aparezca] Sancho el Mayor hasta ahora como un enemigo jurado de Castilla, un homicida que instig6 el asesinato del conde castellano García y un hombre sin escrúpulos dispuesto a todo con tal [de] humillar a la región castellana ${ }^{10}$.

${ }^{7}$ LaCARRA, José María (1976): Historia del Reino de Navarra en la Edad Media, Caja de Ahorros de Navarra, p. 83.

8 Documentos..., p. 110.

9 Meń́ndez Pidal, R. (1940; sexta ed. -por la que citamos-1971): Idea imperial de Carlos $V$, Madrid, Espasa-Calpe, pp. 96 y 113.

10 UbIETO ARTETA, ANTONIO (1960): Estudios en torno a la división del Reino por Sancho el Mayor de Navarra, Pamplona, Diputación Foral, pp. 7-8. Ejemplar de la Biblioteca Nacional de Madrid. 
Si se conoce eruditamente pero no se opera con la existencia de un programa feudal en el siglo XI, Sancho el Mayor aparecerá sin más que ambiciones; se movió en cambio (viene a interpretar Ubieto) por su mentalidad feudal. Vasallajes e incorporaciones logrados por él harán —en cualquier caso- que fuese denominado por un monje catalán coetáneo «rex Ibericus»: Pamplona se convirtió con Sancho en capital de la cristiandad peninsular y de parte del Mediodía francés ${ }^{11}$.

Sabemos por los datos ordenados por Menéndez Pidal que la Rioja se incorpora a Castilla en 1076, y quien lo hizo fue Alfonso VI; más tarde «algún testimonio de 1114 muestra a Alfonso I el Batallador como señor de la Rioja», y la región quedó luego reconquistada por Alfonso VII ${ }^{12}$; se hizo finalmente castellana en 1176, según hemos registrado antes. La Rioja fue por tanto musulmana, más tarde navarra, luego castellana, dependió asimismo de Alfonso I de Aragón, etc.

Nos han aparecido en la anterior trayectoria vascos, monjes y franceses en cuanto integrantes de la historia riojana ${ }^{13}$; en efecto estos componentes inciden en su historia idiomática.

\section{La lengua: las Glosas iberorromances}

Las Glosas Emilianenses se consideran hoy del siglo once «bastante entrado», es decir, de «los primeros decenios del siglo XI» (Manuel Díaz y Díaz), y aun hay quien propone retrasarlas algo más, y son en conjunto -en la edición que hizo Menéndez Pidal- 145; la número 89 constituye el conocido texto que está considerado tradicionalmente como el primero de lengua española.

Reparando en este momento en tal fragmento 89 encontramos rasgos del romance peninsular más primitivo, a saber: cono (asimilación de preposición y artículo); ajutorio (conservación de la sorda intervocálica); get (diptongación en el verbo «ser»); sieculos (diptongación; respecto de la sorda intervocálica conservada Alarcos se pregunta si no se tratará de «una grafía que evita el empleo de $g »)$; face (indistinción gráfica de la confusión de sonoras y sordas, según el mismo Emilio Alarcos); etc. ${ }^{14}$.

Menéndez Pidal estimaba que las Glosas Emilianenses representaban el habla riojana muy impregnada de los rasgos navarro-aragoneses, y Lapesa las tenía

11 Cfr. Ubieto, Introducción..., pp. 142-143.

12 Alvar, M. (1969): El dialecto riojano, México, UNAM, pp. 14-15.

13 Vid. una primera ojeada en ALvar, El dialecto..., pp. 15-27.

14 Cfr. Menéndez Pidal, R. (1986 $\left.{ }^{10}\right)$ : Orígenes del español, Madrid, Espasa-Calpe, pp. 7 y 470-471; Alarcos Llorach, EmLlo, El español, lengua milenaria, Valladolid, Ámbito, 1992, pp. 33-38. 
como muestra del «dialecto navarro-aragonés»; encontramos en ellas rasgos tanto riojanos como navarros y aragoneses - tal como había percibido bien don Ramón-, y de esta manera nos encontramos en realidad ante un conjunto de caracteres que podemos denominar «españoles» o «iberorrománicos»: por eso ha podido hablarse también de sincretismo linguístico a propósito de las mismas.

\section{Berceo}

Un momento posterior de la historia idiomática riojana es el que supone la Vida de Santa Oria, en la que podemos encontrar efectivamente rasgos dialectales.

a) La Rioja es región de $m b$, y vemos así en nuestro poema palonba(s) $(30 \mathrm{~b} ; 37 \mathrm{~b} ; 49 \mathrm{c})$, o palonbar ( $30 \mathrm{~d}$ ), pero una vez aparece la asimilación del grupo consonántico: palomas $\left(46\right.$ b) ${ }^{15}$.

b) Berceo usa constantemente la forma pronominal $l i$, característica de la Rioja Alta en todo el Doscientos según Menéndez Pidal ${ }^{16}$. En Santa Oria se encuentran: «li pusieron» $(9 \mathrm{~b})$; «lis quisiesse» ( $14 \mathrm{~b})$; no obstante, alguna ocurrencia se encuentra de le $(116 \mathrm{c})$.

c) También el demostrativo termina en - $i$ : esti (94 c; 96 a; 97 c; 128 b; etc.) En fin y fuera ya de lo dialectal riojano encontramos un nuevo rasgo:

d) Aparece el artículo ante posesivo: alguna vez parece expresar intensidad afectiva («Que para el su servicio fuesse, que para al non» - $14 \mathrm{c}-$ ), pero en la mayor parte de las ocasiones tal presencia del artículo no se halla - según nuestra percepción- sino al servicio de una conveniencia métrica. Ocurre pues que la constricción métrica se sobrepone - según ocurre siempre en literatura-, ya que el arte es en todo momento artificio ${ }^{17}$.

\section{NOTAS SOBRE EL FUERO DE LEDESMA}

Buena parte del contenido del Fuero de Ledesma - nos dice Federico de Onís- procede del de Salamanca, el cual fue copiado literalmente a veces; esa

15 Citamos por la ed. de Marden, C. Carroll (1928): Cuatro Poemas de Berceo, Madrid, Centro de Estudios Históricos, pp. 73 y ss.

16 Orígenes..., \$66. 3 .

17 Aporta novedades en cuanto a la lengua del valle de San Millán y para la más correcta edición que ha de hacerse de las obras de Berceo, el análisis de García Turza, Claudio y Javier (1996): Una nueva visión de la lengua de Berceo a la luz de la documentación emilianense del siglo XIII, Universidad de la Rioja. 
copia debe proceder «de un manuscrito perdido del Fuero de Salamanca, anterior y original de[1 llamado manuscrito] $\mathrm{C} m{ }^{18}$.

Este Fuero de Ledesma presenta dialectalismos leoneses; en todo caso algunos de sus rasgos son ${ }^{19}$ :

A) En cuanto al vocalismo.

1. Queda sin diptongar en sucesivas ocasiones la $\check{\text { ox }}$ soldos $(\$ \S 4,113$, $121,122,126$, etc.); bono $(s)(\S \S 10,27,108,171$, etc.); bona (\$§135, 137, $138,197)$; orfano $(s)(\$ \S 173,200)$. Parece razonable pensar en la impronta del cultismo en esta ausencia de formas diptongadas.

2. La apócope de la -e en la tercera persona del singular del futuro de subjuntivo aparece nada más iniciarse el texto, y luego se mantiene a lo largo del mismo. Según las comprobaciones de Manuel Alvar, el Fuero de Ledesma revela en esto también que sigue el manuscrito original de la copia llamada $\mathrm{C}$ del Fuero de Salamanca ${ }^{20}$.

3. La -e se conserva dialectalmente en cambio en las palabras lide ( $\$ 4)$, heredade $(\$ \S 78,125,126,127,130,145$, etc.), uerdade $(\$ 123)$, huespede $(\S$ $162)$, edade ( $\$ 200), \ldots$

4. Epéntesis de yod hay en prazio 'plazo' $(\$ \S 78,89)$, segurancia $(\$ \S 89$, 107), o forcia (\$95).

B) En cuanto al consonantismo.

1. CL- da una solución dialectal:xamar $(\$ \S 76,92)$.

2. La prepalatal fricativa sonora $\check{z}$ se mantiene así en las derivaciones de LY y C'L, y está transcrita muchas veces con $y$, o con $g i, \ldots$ conceyo $(\$ \S 6,32$, 42,43 , etc.), mugier $(\S 8)$, ayeno o ayena $(\S \S 19,40$, etc.), oueya $(\mathrm{s})(\S \S$ $33,34,35)$, moyones $(\$ 39)$, coneyos $(\$ 152)$, oyo $(\$ 180)$.

3. No se da la reducción de -MB- en palonba $(\$ \S 82,83,84)$.

4. Aparecen las formas calonmia ( $\$ \S 31,59)$ o calomia(s) $(\$ \S 34,36,41$, $61,80,103,167,194)$; la primera puede ser una solución castellana, mientras la segunda es dialectal.

5. El otro grupo - $\mathrm{M}^{\prime} \mathrm{N}$ - se manifiesta en la voz omne $(\$ \S 4,13)$; según Menéndez Pidal «en el siglo XIII coexisten en diversas regiones las formas nomne, nomre y nombres ${ }^{21}$.

18 Vid. CASTRO, A. y DE ONIs, F. (1916): Fueros leoneses de Zamora, Salamanca,Ledesma y Alba de Tormes, Madrid, Centro de Estudios Históricos, pp. 209 y ss.; es la edición por la que citamos.

19 Hacemos el análisis a partir de la lectura de los 200 primeros artículos o preceptos del Fuero.

20 Alvar, M. (1968): El Fuero de Salamanca, Universidad de Granada, pp. 35 y 149.

${ }^{21}$ MenÉndez PIDAl, R. (1989): Manual de Gramática histórica española, Madrid, EspasaCalpe, vigésima ed., p. 160. 
6. Las voces yglisia $(s)$ o ygresia $(\$ 113)$, dobrado $(\$ 148)$ o preyto $(\$ 169)$ muestran un caso de asimilación vocálica (yglisia), y asimismo un dialectalismo según el cual la $L$ se ha hecho $r$.

7. Hay un conocido leonesismo en iulgar y otras formas del mismo verbo $(\$ \S 20,75,76,86,89,171)$, en selmana $(\$ 160)$, o en portalgo $(\S 163)$.

\section{LOS ESTUDIOS SOBRE REPOBLACIÓN Y LINGUÚSTICA DE LA PROVINCIA DE MálaGa}

Historiadores y filólogos se han hecho cargo en estos últimos treinta años de la repoblación del reino de Granada, y de las consecuencias idiomáticas que de ella se derivaban.

En lo que respecta a Málaga y su provincia, la edición por Rafael Bejarano de Los Repartimientos de Álora y de Cártama (Málaga, Eds. del Aula de Cultura de Peña Malaguista, 1971), promovió una pequeña monografía de Manuel Alvar: «Repoblación y linguística: los Repartimientos de Alora y de Cártama» (en la revista local Jábega, $\mathrm{n}^{2} 3,1973$, pp. 91-95). En estas páginas Alvar hace consideraciones demográficas, y asimismo observaciones lingüísticas: sobre el caos gráfico que testimonia los procesos en marcha respecto de las sibilantes, sobre la neutralización de $l$ y $r$, etc.

Entre 1975 y 1977 el propio Alvar amplió mucho sus notas -en particular por lo que se refiere a los datos demográficos-, en un artículo amplio que sin embargo ha permanecido inédito hasta ahora mismo: nos referimos al escrito «Historia y linguística. Los Repartimientos de la provincia de Málaga (1485-1496)», que está en el BRAE, LXXXI, 2001, pp. 5-44. Aunque este artículo recoge casi entero el texto del anterior, en algún momento el conjunto resulta sin embargo más claro quizá en la primera versión.

Análisis demográficos primarios llevó a cabo el medievalista José E[nrique] López de Coca: en La tierra de Málaga a fines del siglo XV (Universidad de Granada, 1977; cfr. las pp. 103-105), o en «El Repartimiento de Vélez-Málaga» (Cuadernos de Historia, 7, Madrid, CSIC, 1977, pp. 357-439; cfr. las pp. 368-373).

Indicaciones sobre cómo en el reino de Granada a raíz de su conquista entraron «de 35.000 a 40.000 colonos procedentes de la Andalucía cristiana, Extremadura, Castilla la Nueva y Murcia» se hallan en el libro de Miguel Angel Ladero Quesada España en 1492 (Madrid, Hernando, 1978).

Asimismo abordó «la procedencia de los repobladores» M[anuel] Acién Almansa en Ronda y su serranía en tiempo de los Reyes Católicos (Universidad de Málaga, 1979, I, pp. 170-182). 
Al haberse publicado más tarde los Repartimientos de la capital, Manuel Alvar Ezquerra ha tenido en cuenta la nueva documentación, y ha presentado un cuadro demográfico de conjunto en su trabajo Conquista, emigración, repoblación y habla (Ayuntamiento de Málaga, 1994).

Por nuestra parte asimismo, y a la vista de lo que había empezado a hacer Manuel Alvar en su escrito de 1973, elaboramos para una reunión de historiadores la comunicación «Orígenes del andaluz y de la norma lingüística de Sevilla» (aparecida en el volumen de actas Andalucía entre Oriente y Occidente, Diputación Provincial de Córdoba, 1988, pp. 765-772). 